\title{
Student Evaluation of an OSCE in Community Health Nursing Clinical Course at Faculty of Nursing, Tanta University
}

\author{
Amaal M. Al-Zeftawy ${ }^{1}$, Samia E. Khaton ${ }^{2}$ \\ ${ }^{1}$ Assistant professor of Community Health Nursing \\ ${ }^{2}$ Lecturer of Community Health Nursing, \\ Faculty of Nursing, Tanta University, Tanta, Egypt
}

\begin{abstract}
:
Background: - The Objective Structured Clinical Exam (OSCE) is a comprehensive, structured and consistent approach for assessing aspects of the student's clinical competence with maintenance of high objectivity.

Aim of the study: to assess student evaluation of an OSCE in community health nursing clinical course at Faculty of Nursing, Tanta University.

Materials and methods: - Study Design: A descriptive cross section study design was used for the study.

Study setting: The study was conducted in Faculty of Nursing, Tanta University.

Sample: A non probability convenient sample of (151) nursing students who completed their community health nursing OSCE examination.

Tool of data collection: a self administered questionnaire sheet was used including the following parts: - Part 1: socio-demographic characteristic of the students. Part 2: Pierre et al., 2004 OSCE evaluation questionnaire which was adapted in this study. It is divided into 4 sections which contain32 items. Only 29 items of Pierre et al., 2004 questionnaire were used in this study and few items were modified to give a clear meaning in Arabic version.

Results: - OSCE was considered as a fair examination method by $78.1 \%$ of students and $58 \%$ of them felt that it provides a true measure of essential clinical skills. Nearly two thirds (64.2\%) of the studied students reported that, OSCE is less stressful than other exams, still one third of them (33.8\%) felt that the exam was very stressful.
\end{abstract}

Conclusion: OSCE is a realistic assessment for the community health nursing clinical course. It could assess a wide range of learned materials; it is a fair exam and covered a wide range of knowledge.

Recommendation: the present study recommended that, OSCE should be continued to use as a method of evaluating clinical practice in a combination with traditional method.

Keywords: OSCE, evaluation, competence, comprehensive.

\section{Introduction}

In the last two decades, a rapid extensive change has occurs in the assessment methods of medical education. Many of introduced assessment methods have been developed and focused mainly on clinical procedural skills, communication skills and professionalism ${ }^{(1-3)}$. Objective Structured Clinical Examination (OSCE) is one of well established practical tests used to assess specific clinical skills. Ronald Harden was introducing it for the first time in medical education at 1975, at the University of Dundee to assess skills of clinical performance. Now, it is used in other branches including nursing, dentistry, and pharmacy. OSCE becomes a popular tool for assessing competency in clinical nursing. It has been used in medical schools for both formative and summative evaluations to validate clinical skills by using of 'standardized patients' $(4,5)$.

OSCE exam is more commonly used to test trainees from various disciplines in healthcare ${ }^{(6)}$. Also, many clinical educational institutions give more attention to it because of high level of objectivity, fairness, content validity, reliability, creditability of the achieved skills, creating learning motivation and maintain students 'satisfaction $^{(4,7-10)}$.

Steady increase in number of students enrolled at Egyptian nursing faculties might increase the chances of malpractice which may affects patient's conditions. Moreover, with large groups of nursing students, the acquisition of critical thinking abilities and problem solving skills and are difficult to manage. Traditional clinical nursing examinations are not considered as a standardized tools to assess students' clinical competency, and clinical reasoning skills. In which teachers conduct the assessment of student performance and give summative scores. So, it is a challenge to have an objective assessment tool to assess students' clinical competencies in a comprehensive manner especially with the increased number of students ${ }^{(11)}$.

The OSCE is designed through creating a multi-station arrangement in which a student perform an assigned skill or conduct assessment using a standardized patient, while being watched by assessor. The student is assessed in different clinical competencies through moving from station to the next one such as giving 
injection, nursing diagnoses, history taking, interpretation of clinical data, and so on. The students are rotated in between stations that allotted equal amounts of time. The stations can be ranged from two to more than 20 stations. As the number of stations increased, the validity of the examination is increased also. A ring of a bell and stopwatch are used to control interring and leaving of the station. At the end of the specified time, the student listen the bell sound and leave the station and moving to the next one. And so, each student performs the same tasks and was marked and assessed according to the same assessment criteria on the examiner's mark sheet. The assessor use the checklist or rating scale to rate each student's performance through direct observation. The final mark sheet can be based on a performance checklist- or a combination of a checklist and a global score. ${ }^{(1,4,12,13)}$.

OSCE can objectively assess other important aspects of clinical experiences, such as problem-solving abilities, physical examination skills, technical skills, interpersonal skills, decision making abilities and patient treatment skills. Moreover, OSCE is being used worldwide to provide formative and summative evaluation in various disciplines which include ongoing and final assessment ${ }^{(1.4,12,13)}$.

The possibility of conducting case studies, small scenarios, simulations and standardized patient (SP) is considered a great advantage of OSCE as it integrates theory and practice. It provides a safe environment for the students to improve their own learning abilities. Also, it overcomes the need for large number of clinical instructors requested with a high number of students ${ }^{(13-18)}$.

Consistent and equitable marking of OSCE stations is essential. However, it recognizes that examiners may have potential subjective opinions when rating students' scores. This can be overcomes through recruiting clinical instructors from different departments in the college plus those in the department to ensure that the objectivity is sustained. Then, orient the examiners to the examiners' instruction, and scoring of the students using the checklist (mark sheets) ${ }^{(19)}$. Jones et al. (2010) argue that although consistency of marking is enabled by a structured mark sheet, the examiner has a crucial role in ensuring reliability also and strict preparation of all examiners is therefore essential ${ }^{(20)}$. The main role of the examiner is to observe and record the student's performance ${ }^{(21)}$. Rennie and Main (2006), ensuring that, the training of assessors is also crucial to ensure consistency and reliability in the marking criteria ${ }^{(22)}$.

One of the obligatory nursing courses that are provided for the fourth year nursing students in Faculty of Nursing, Tanta University is the community health nursing. OSCE was first introduced in the Faculty nearly since four academic years. It was used to assess clinical performance of nursing students' in, maternity nursing, pediatric nursing and medical surgical nursing then since three years it was used in community health nursing. No one try to assess students' evaluation for this exam in community health nursing department since that time. Faculty staff and students were exposed to a new assessment tool for the first time which assesses a variety of students' knowledge and skills in an objective and structured way. Evaluation of OSCE experience by students helps to enhance its acceptance as a relatively new assessment tool and refine some of the deficiencies observed in the preparation and conduct of the process ${ }^{(18)}$. Therefore, students' experience and feedback about the use of this new assessment method deserves to be investigated.

\section{Aim of the study}

The aim of this study was to assess student evaluation of an OSCE in community health nursing clinical course at Faculty of Nursing, Tanta University.

\section{Research questions}

What are the nursing student's feedback regarding OSCE as an evaluating method, its validity and reliability? What are the nursing student's feedback regarding OSCE preparation and quality of OSCE performance?

\section{Materials And Method}

Study Deign: A descriptive cross section study design was used.

Study setting: The study was conducted in Faculty of Nursing, Tanta University.

Sample: A non probability convenient sample of (151) nursing students who completed their community health nursing OSCE examination, and have willingness to participate in this study were included in the study.

\section{Tools of data collection}

Data was collected with the use of a self administered questionnaire sheet.

This tool included the following parts:-

Part 1: socio-demographic characteristic of the students (sex, age, academic year, study semester and pervious OSCE exam). 
Part2: Pierre et al., 2004 ${ }^{(18)}$ questionnaire for evaluation of OSCE was adapted in this study. The questionnaire includes 32 items classified into 4 sections. In this study, only 29 items of the questionnaire were used, and few items were modified to clarifying the meaning in Arabic translation.

\section{The questionnaire used in the current study consists of four main parts: First part :- Evaluation of the OSCE attributes:-}

This part includes thirteen items, assesses nursing students' evaluation of the OSCE attributes such as area of knowledge covered, the fairness of the exam, , time of each station, and the administration and organization of OSCE (Table 1 ). Students rating their responses on a four point scale ranging: 'agree', ' neutral', 'disagree', and no comment'.

\section{Second part: - Evaluation of the quality of OSCE performance:}

Eight items involving students' awareness of the nature of the exam, structure of the exam, tasks of the exam and the adequacy of the time at each station (Table2).

Third part: - Evaluate perception of the student toward validity and reliability of the OSCE scoring and objectivity: This part assesses nursing students' evaluation of the scoring and objectivity of the OSCE and it include four items addressing the standardization of the OSCE score, objectivity and its usefulness (Table 3). Students were asked to rate their responses for the second and third parts on a three point scale ranging: 'not at all', 'neutral' and 'to a great extent

Fourth part: - Students' opinion about the usefulness of OSCE as an assessment tool compared to the previous methods. Students rating responses on three point scale ranging difficult, undecided and easy.

'Content validity of the questionnaire translated to Arabic was obtained by the five panels of experts in the field. The reliability of the questionnaire was done using Alpha Cronbach's test. Alpha score for the 29 item questionnaire is 0.89 . SS

\section{1- Ethical Considerations:}

\section{Method}

An approval to conduct the study was obtained from Dean of the faculty of nursing and head of community health nursing department to conduct the study. Also an ethical approval was obtained from all students at Community Health Nursing department. Students were informed about the nature of the study and that their participation is voluntary; assure the students about the confidentiality of data collected.

\section{2-Translation of the Questionnaire:}

The questionnaire was translated into Arabic by the researchers. Back translation technique was used to ensure the validity of translation by English language expertise from Faculty of Education, English Department. The two versions were reviewed by a lecturer from Faculty of Nursing, and modifications were made accordingly.

\section{3- Preparations for the OSCE:}

OSCE exam was carried out in the clinical skills lab. The community health nursing OSCE stations were prepared by the department staff. The community health nursing OSCE composed of four stations assessing skills and one station is a documentation stations included axillary temperature, insulin injection filling the syringe skills, baby cord dressing and weighing the infant by using baby diaper (alternated with baby cord dressing). Station of the documentation included a picture of the breast self examination technique of and recording the abnormality to be find during this procedure. Each station is 3 minutes duration.

\section{4- Administration of the OSCE:}

The OSCE answer book was prepared including a cover sheet, the instruction sheet and a separate sheet for each station. For each clinical procedure an observational checklist was prepared. The instructions told to the students by one of the examiners before starting the OSCE. Students were asked to demonstrate both psychomotor skills and clinical knowledge. All students in the OSCE lab went through the same stations simultaneously by moving around the stations. They moved each 3 minutes when hearing the bell sound. Each group of students completes the five stations over 15 minutes.

\section{5- Collecting Students' Feedback:}

Data was collected with the use of a self administered questionnaire. All students were told about the aim of the study, and its significance. They were asked to give their feedback about OSCE as an assessment 
method for their clinical skills. The questionnaires were distributed to all students after completion of their community health nursing OSCE. Students were asked to evaluate the structure, content, and organization of the OSCE, rate the objectivity and quality of performance of the OSCE process, and to give their opinion about the usefulness of the OSCE as an assessment tool compared to other forms which they had experienced such as (essays, multiple choice questions, long and short cases, general clerkship rating).

\section{6- Data Analysis:}

The data were coded, entered and analyzed using SPSS (version 20). Descriptive statistics (frequency numbers and percentages) identified demographic characteristics and students responses to the questionnaire. Chi-square test analyzes the differences and a significant difference was set at $\mathrm{P}$ value $<0.05 \%$.

Table 1: represents nursing students' evaluation of the OSCE attributes. The table revealed that most of the students(78.1\%) agreed that OSCE was fair and nearly two thirds of them $(65.6 \%, 64.9 \%$, $64.2 \%, 63.6 \%$ and $62.3 \%$ ) respectively reported that OSCE minimized chance of failing, covered a wide range of knowledge, less stressful than other exams, allowed student to compensate in some areas and was well administered. Only more than half of the studied nursing students $(58.9 \%, 58.3 \%, 57.6 \%$ and $55 \%)$ respectively reported that the OSCE covered wide range of clinical skills, the exam well structured and sequenced, the nursing students aware of level of information needed and the exam needed more time at station.

Although nearly two thirds $(64.2 \%)$ of the studied students reported that OSCE less stressful than other exams; still one third of them (33.8\%) felt that the exam was very stressful and intimidating $(29.8 \%)$. A considerable percentage of studied nursing students were neutral about many of the attributes of OSCE exam, such as the OSCE exams well structured and sequenced(23.8\%), the exam had stressful nature and intimidating (19.9\%), the exam need for more time at stations and minimized chance of failing (18.5\%).

In relation to nursing students' evaluation of the quality of OSCE performance, Table (2) showed that most of the studied nursing students (70.9\%) reported that the tasks students were asked to perform in OSCE were fair and reflected those which were taught (51\%). Nearly two thirds $(65.6 \%, 64.9 \%$ and $62.9 \%)$ respectively of studied nursing students reported that they were fully aware of the nature of the exam, instructions of the exam were clear and unambiguous and setting and context at each station felt authentic.

On the other hand, more than one third of the studied nursing students were neutral about the tasks of the exam reflected those taught and the sequence of stations was logical and appropriate and nearly one third(31.1\%) were neutral about the setting and context at each station felt authentic and exam provided opportunities to learn.

Table (3) represents nursing students' perception of validity and reliability of OSCE scoring and objectivity. The table revealed that more than half (59.6\% and 58.9\%) respectively of studied nursing students reported that OSCE scores were most affected by students personality, ethnicity and gender and believed that OSCE exam scores provided true measures of essential clinical skills in community health nursing . however, a considerable percentage of studied nursing students take the neutral position concerning OSCE exam as useful experience (38.4\%), OSCE scoring measure (33.8\%) and OSCE affected by personality, ethnicity and gender $(31.1 \%$.)

Table (4) represents Student rating of assessment formats. Students were asked to rate the following assessment instruments to which they had been exposed (multiple choice questions, essays / short answer questions, general clerkship ratings, OSCE). A Likert scale was used to assess each according to the evaluative labels (Table 4). The table revealed that more than one third (38.4\%) of students felt that OSCE rating was the easiest, while 31.8 rated MCQ as a more difficult form of assessment. The OSCE and MCQ were considered the fairest assessment format (29.8), and essays (27.2) to a lesser extent. OSCE (31.8) and essays (27.8) were considered the most useful learning experiences. Compared to the other assessment formats, $31.1 \%$ considered that the clerkship ratings should be used most in the clinical years. A significance statistical difference was found between the students rating of OSCE formats as the fairest, the OSCE as the formats that do you learn most and should be used often in clinical examination $\mathrm{P}<0.05$.

Table 1: Nursing students' evaluation of the OSCE attributes.

\begin{tabular}{|l|l|l|l|l|l|l|l|l|l|}
\hline \multicolumn{2}{|l}{ Question } & \multicolumn{2}{|l|}{ Agree } & \multicolumn{2}{|l|}{ Disagree } & \multicolumn{2}{|l|}{ Neutral } & \multicolumn{2}{l|}{ comment } \\
\cline { 3 - 10 } \cline { 3 - 9 } & $\mathbf{N}$ & $\mathbf{\%}$ & $\mathbf{N}$ & $\mathbf{\%}$ & $\mathbf{N}$ & $\mathbf{\%}$ & $\mathbf{N}$ & $\mathbf{\%}$ \\
\hline 1. & Exam was fair & 118 & 78.1 & 15 & 9.9 & 16 & 10.6 & 2 & 1.3 \\
\hline 2. & Wide knowledge area covered & 98 & 64.9 & 25 & 16.6 & 25 & 16.6 & 3 & 2.0 \\
\hline 3. & Needed more time at stations & 83 & 55.0 & 37 & 24.5 & 28 & 18.5 & 3 & 2.0 \\
\hline 4. & Exams well administered & 94 & 62.3 & 24 & 15.9 & 27 & 17.9 & 6 & 4.0 \\
\hline
\end{tabular}


Student Evaluation Of An OSCE In Community Health Nursing Clinical Course At Faculty...

\begin{tabular}{|l|l|l|l|l|l|l|l|l|l|}
\hline 5. & Exams very stressful & 51 & 33.8 & 61 & 40.4 & 30 & 19.9 & 9 & 6.0 \\
\hline 6. & Exams well structured \& sequenced & 88 & 58.3 & 21 & 13.9 & 36 & 23.8 & 6 & 4.0 \\
\hline 7. & Exam minimized chance of failing & 99 & 65.6 & 23 & 15.2 & 28 & 18.5 & 1 & .7 \\
\hline 8. & OSCE less stressful than other exams & 97 & 64.2 & 25 & 16.6 & 23 & 15.2 & 6 & 4.0 \\
\hline 9. & Allowed student to compensate in some areas & 96 & 63.6 & 27 & 17.9 & 24 & 15.9 & 4 & 2.6 \\
\hline 10. & Highlighted areas of weakness & 69 & 45.7 & 47 & 31.1 & 29 & 19.2 & 6 & 4.0 \\
\hline 11. & Exam intimidating & 45 & 29.8 & 70 & 46.4 & 30 & 19.9 & 6 & 4.0 \\
\hline 12. & Student aware of level of information needed & 87 & 57.6 & 30 & 19.9 & 28 & 18.5 & 6 & 4.0 \\
\hline 13. & Wide range of clinical skills covered & 89 & 58.9 & 28 & 18.5 & 27 & 17.9 & 7 & 4.6 \\
\hline
\end{tabular}

Table 2: Nursing students' evaluation of the quality of OSCE performance.

\begin{tabular}{|l|l|l|l|l|l|l|l|}
\hline \multicolumn{2}{|l|}{ Question } & \multicolumn{2}{l|}{ To great extent } & \multicolumn{2}{l|}{ Neutral } & \multicolumn{2}{l|}{ Not at all } \\
\cline { 3 - 7 } & Fully aware of nature of exam & 99 & 65.6 & 44 & 29.1 & 8 & 5.3 \\
\hline 1. & Tasks reflected those taught & 77 & 51.0 & 52 & 34.4 & 22 & 14.6 \\
\hline 2. & Time at each station was adequate & 77 & 51.0 & 45 & 29.8 & 29 & 19.2 \\
\hline 3. & Setting and context at each station felt authentic & 95 & 62.9 & 47 & 31.1 & 9 & 6.0 \\
\hline 4. & Instructions were clear and unambiguous & 98 & 64.9 & 39 & 25.8 & 14 & 9.3 \\
\hline 5. & Tasks asked to perform were fair & 107 & 70.9 & 34 & 22.5 & 10 & 6.6 \\
\hline 6. & Sequence of stations logical and appropriate & 86 & 57.0 & 52 & 34.4 & 13 & 8.6 \\
\hline 7. & Exam provided opportunities to learn & 83 & 55.0 & 47 & 31.1 & 21 & 13.9 \\
\hline 8. & Exyyyyyyyy \\
\hline
\end{tabular}

Table (3) Nursing students' perception of validity and reliability of OSCE scoring and objectivity

\begin{tabular}{|c|c|c|c|c|c|c|c|}
\hline \multicolumn{2}{|c|}{ Question } & \multicolumn{2}{|c|}{$\begin{array}{l}\text { To great } \\
\text { extent }\end{array}$} & \multicolumn{2}{|c|}{ Neutral } & \multicolumn{2}{|c|}{ Not at all } \\
\hline & & $\mathbf{N}$ & $\%$ & $\mathbf{N}$ & $\%$ & $\mathbf{N}$ & $\%$ \\
\hline 1. & $\begin{array}{l}\text { OSCE exam scores provide true measure of essential clinical } \\
\text { skills in community health nursing }\end{array}$ & 87 & 57.7 & 51 & 33.8 & 13 & 8.6 \\
\hline 2. & OSCE scores are standardized & 90 & 59.6 & 40 & 26.5 & 21 & 13.9 \\
\hline 3. & OSCE practical and useful experience & 85 & 56.3 & 58 & 38.4 & 8 & 5.3 \\
\hline 4. & Personality, ethnicity and gender will not affect OSCE scores & 89 & 58.9 & 47 & 31.1 & 15 & 9.9 \\
\hline
\end{tabular}

Table (4) Student rating of assessment formats.

\begin{tabular}{|c|c|c|c|c|c|c|c|c|}
\hline Question: & \multicolumn{2}{|c|}{ Difficult } & \multicolumn{2}{|c|}{ Undecided } & \multicolumn{2}{|c|}{ Easy } & \multirow[t]{2}{*}{$\mathbf{X}^{2}$} & \multirow[t]{2}{*}{$\mathbf{P}$} \\
\hline Which of the following formats is easiest? & $\mathbf{N}$ & $\%$ & $\mathbf{N}$ & $\%$ & $\mathbf{N}$ & $\%$ & & \\
\hline MCQ & 48 & 31.8 & 58 & 38.4 & 45 & 29.8 & 5.880 & 0.208 \\
\hline Essay/SAQ & 42 & 27.8 & 62 & 41.1 & 47 & 31.1 & & \\
\hline OSCE & 32 & 21.2 & 61 & 40.4 & 58 & 38.4 & & \\
\hline Clerkship ratings & 40 & 26.5 & 67 & 44.4 & 44 & 29.1 & & \\
\hline Question: & \multicolumn{2}{|c|}{ Unfair } & \multicolumn{2}{|c|}{ Undecided } & \multicolumn{2}{|c|}{ Fair } & & \\
\hline Which of the following formats is fairest? & $\mathbf{N}$ & $\%$ & $\mathbf{N}$ & $\%$ & $\mathbf{N}$ & $\%$ & 10.506 & $\mathbf{0 . 0 3 3} *$ \\
\hline MCQ & 52 & 34.4 & 54 & 35.8 & 45 & 29.8 & & \\
\hline Essay/SAQ & 40 & 26.5 & 70 & 46.4 & 41 & 27.2 & & \\
\hline OSCE & 42 & 27.8 & 64 & 42.4 & 45 & 29.8 & & \\
\hline Clerkship ratings & 49 & 32.5 & 63 & 41.7 & 39 & 25.8 & & \\
\hline Question: & \multicolumn{2}{|c|}{ Learn very little } & \multicolumn{2}{|c|}{ Undecided } & \multicolumn{2}{|c|}{ Learn a lot } & & \\
\hline $\begin{array}{l}\text { From which of the following formats do you learn } \\
\text { most? }\end{array}$ & $\mathbf{N}$ & $\%$ & $\mathbf{N}$ & $\%$ & $\mathbf{N}$ & $\%$ & 12.151 & $\mathbf{0 . 0 1 6}^{*}$ \\
\hline MCQ & 57 & 37.7 & 58 & 38.4 & 36 & 23.8 & & \\
\hline Essay/SAQ & 51 & 33.8 & 58 & 38.4 & 42 & 27.8 & & \\
\hline OSCE & 42 & 27.8 & 61 & 40.4 & 48 & 31.8 & & \\
\hline Clerkship ratings & 50 & 33.1 & 64 & 42.4 & 37 & 24.5 & & \\
\hline Question: & \multicolumn{2}{|c|}{ Used much less } & \multicolumn{2}{|c|}{ Undecided } & \multicolumn{2}{|c|}{ Used much more } & & \\
\hline $\begin{array}{l}\text { Which of the following formats should be used } \\
\text { more often in the clinical years of the programme? }\end{array}$ & $\mathbf{N}$ & $\%$ & $\mathbf{N}$ & $\%$ & $\mathbf{N}$ & $\%$ & $\mathbf{1 7 . 2 1 2}$ & 0.002* \\
\hline MCQ & 60 & 39.7 & 49 & 32.5 & 42 & 27.8 & & \\
\hline Essay/SAQ & 44 & 29.1 & 61 & 40.4 & 46 & 30.5 & & \\
\hline OSCE & 48 & 31.8 & 58 & 38.4 & 45 & 29.8 & & \\
\hline Clerkship ratings & 42 & 27.8 & 62 & 41.1 & 47 & 31.1 & & \\
\hline
\end{tabular}

\section{Discussion}

One of the effective assessment methods for assessing clinical skills in most medical professions, and for dedicating curriculum problem areas is objective structured clinical examinations (OSCEs) ${ }^{(7,12)}$. The findings of the current study indicated that the student's feedback about the attributes of OSCE and quality was positive. These findings were in agreement with other researches' findings (Alinier, 2003; Pierre et al., 2004; Eswi et al., 2013 and El-Nemer\&Kandeel2009) ${ }^{(21,18,12,13) .}$

According to the current study, most of the students reported that OSCE was fair and nearly two thirds of them respectively reported that OSCE minimized chance of failing, covered a wide range of 
knowledge, allowed student to compensate in some areas, less stressful than other exams and was well administered. The results of the present study in accordance with Eswi et al., 2013 who found that more than half of the students indicated that OSCE was not stressful than the other assessment method, it covers a wide range of clinical skills, motivated them for further learning and considered as a fair assessment tool, in which a broad area of knowledge allowed them to compensate in some areas and minimized their chances of failing ${ }^{(12)}$. Also the findings of the present study are similar to the research work reported by Kurzet al.,2009 ${ }^{(9)}$ and ElGilanyet al.,2010 ${ }^{(23)}$ who mentioned the main advantages of OSCE is putting the students in a real situation.

In relation to student's perception of the OSCE the results of the present study are consistent with Mater et al., 2014 ,Abdel Nasser et al., 2012 and Eftekhar et al., 2012 who found that between half , two third of and the majority of their studied subjects perceived OSCE as a fair and stressful exam, improve their overall final grade and increases their chance of excellence ${ }^{(26-28)}$. In the present study although nearly two thirds of the studied students reported that OSCE less stressful than other exams, still one third of them felt that the exam was very intimidating and stressful. These findings are in accordance with a study conducted by El Nemer \& Kandeel, (2009) who found that their studied subjects were perceived OSCE as a stressful experience and intimidating by a considerable percentage of their students, especially first year nursing students. Their rationalization for these results was that this perception could be due to that this was the first time that the OSCE has been implemented at Faculty of Nursing, Mansoura University ${ }^{(13)}$. However, in our study the students of fourth year pass through this exam before in previous two years which makes a lot of them feel less stress.

Nursing students' stressful experience with OSCE was also reported in other studies (Pierre et al., 2004 and Ryan et al., 2007) ${ }^{(18,29))}$ On the other hand Brosanan et.al., 2006 reported that the majority of the students of the nursing students in his survey perceived OSCE as a stressful method and they agreed that there were sufficiently prepared for the format and content of examination ${ }^{(30)}$. While, Bakhsh et al., 2009 reported that because OSCE is not well established in nursing education so that OSCE is a stressful method than other methods of assessment ${ }^{(31)}$. Anxiety, lack of confidence was associated with a new assessment and inadequate preparation for the examination may be influence student perception of the OSCE. Also the students completed the questionnaire immediately after the final examination; hence the students' stress and fatigue should be taken into consideration.

Regarding to the student's view about their preparation of OSCE, more than half of the studied nursing students respectively reported that the OSCE covered wide range of clinical skills, the exam well-structured and sequenced, the nursing students aware of level of information needed and the exam needed more time at station. These findings agreement with Selim et al., 2012 who mentioned that the majority of the students consistently appraised the OSCE and reported that it was well structured and instructions were clear and unambiguous, time for each station was adequate and the sequence of the station was logic and appropriate ${ }^{(8)}$. Also these results in agreement with Mater et al., 2014 who found that around half of studied subjects considered that OSCE was well structured exam with clear instruction and realistic scenario ${ }^{(25)}$. Dharam et al., 2013 found that most of the students agree that OSCE is fair, standardized and clear method of assessment. However, few students felt that instructions were not clear and were ambiguous; time provided was not sufficient; and the examination was stressful $^{(1)}$.

In the present study most students provided positive feedback about the quality of OSCE performance in terms of the sequence of OSCE stations, the reflection of the tasks taught, the clarity of the instructions of the exam and the time at each station. These findings are consistent with ${ }^{(30,32,33)}$ study results. Feedback from nursing students suggests that OSCE is an objective tool for evaluating clinical skills. Students viewed OSCE scores as a true measure for essential clinical skills being evaluated, standardized, and not affected by student's personality or social relations. OSCE was seen as a positive and a useful practical experience by most students. This results congruent with ${ }^{(9,34)}$ study results in which nursing students perceived OSCE as a favorable experience that should be repeated regularly. The findings of the present study are also consistent with Pierre et al. (2004) who reported that most students perceived OSCE as comprehensive, a useful practical experience, covered a wide range of knowledge and clinical competencies ${ }^{(18)}$.

However, Mitchell et al. (2009) reported that in contrast with various positive specifications of OSCE, for better usage of this method in assessing clinical skills of nursing students, it is essential that this method is used besides other methods of assessment so that more accurate and favorable results will be found for judgment ${ }^{(35)}$.On the other hand this findings were against that reported by Delavaretal., 2013 who found that around half of students expressed their opinion that the OSCE test was a stressful method for assessment. Moreover, they reported that the time allocated to each station was not satisfactory ${ }^{(28)}$. On the other hand, in the current study more than one third of the studied nursing students were neutral about the tasks of the exam reflected those taught and the sequence of stations was logical and appropriate and nearly one third were neutral about the setting and context at each station felt authentic and exam provided opportunities to learn. 
According to the view of students toward the validity and reliability of OSCE more than half of studied nursing students reported that OSCE scores were most affected by student's personality, ethnicity and gender and believed that OSCE exam scores provided true measures of essential clinical skills in community health nursing. These results in agreement with Mater et al., 2014 who reported that around two third of student believed that the score was standardized and reflected actual measure of essential clinical skills and around three quarter of students viewed that OSCE reflected those taught and opportunities to learn ${ }^{(25)}$. These results is also agreed with Raheel and Naeem2013 who found that, over half of student believed that OSCE was standardized and more than one third of them agreed that their performance on the examination was a true reflection of their clinical skills ${ }^{(36)}$.This result were convenience with Jawad et al. 2013 who found that the majority of students expressed that OSCE was recognized as a useful learning experience and the examination provided them with an opportunity to learn ${ }^{(37)}$. Also these results were supported by other research studies ${ }^{(38,39)}$.

Traditional nursing education is based on the transfer of knowledge. However, knowledge is not only the main source of education based on skills and competencies but this type of education is focused also on professional attitudes and psychomotor skills. Such education provides for safe and effective nursing practice without the need of direct supervision. Its implementation needs the refinement of learning outcomes and the use of appropriate methods of assessment, e.g. Objective Structured Clinical Examination (OSCE) ${ }^{(40)}$. Regarding student rating of assessment formats the results of the present study revealed that more than one third of students felt that OSCE rating was the easiest, while nearly one third of them rated MCQ as a more difficult form of assessment. The OSCE and MCQ were considered the fairest assessment format by more than one quarter of the students. Essays and OSCE were the most useful experiences in learning process. Compared to the other assessment formats, nearly one third considered that the clerkship ratings should be used most in the clinical years.

These results were convenience with Eswietal.,2013 who found that about half of the studied subjects reported that MCQ are the easiest formats, while only more than one third of them reported that OSCE is the easiest. More than half of the them reported that OSCE is the fairest compared to more than one quarter of the students indicated that MCQ is the fairest. More than one third of the students reported that OSCE formats is that they learned most versus one quarter of them who considered MCQ is the formats they learned most. Three quarters of the students reported that OSCE formats should be used more in clinical examination ${ }^{(12)}$. Also Pierre etal., 2004 reported that students perceived the OSCE to be fairer than any other assessment format to which they were exposed and students have traditionally viewed the end of- clerkship assessment as a 'high-stake' examination and also perceive it as predictive of their performance at their final MB examination ${ }^{(18)}$. The findings reported by Pierre etal., 2004 were supported also by Eldarir and Abd el Hamid 2013 who foundthat students mentioned that OSCE was a meaningful and the fairest method of assessing clinical skills ${ }^{(24)}$ and Smith et al., (2012) made comparison between different methods of assessing midwifery students' clinical skills, they found that the results indicated that none of the assessment methods of clinical skills can provide complete information about the students' skills but OSCE method can be used as a very valuable method for assessing clinical competency of students because of appropriate reliability in comparison to methods such as worksheet, clinical observance, and others ${ }^{(40)}$.

\section{Conclusion}

In summary, the findings highlight that OSCE is a meaningful and fair form of assessment tool for clinical skills in nursing and that it has had a positive effect on nursing curriculum. It could assess a wide range of learned material and covered a wide range of knowledge. The conduct of OSCE is congruent to the findings of most of the studies done on conducting OSCE with nursing students.

\section{Recommendations}

Based on findings of the current study, it is recommended that:

1. OSCE must be used as an integral part of the clinical evaluation system / students' assessment at the under graduate.

2. OSCE should be used as a method of evaluating clinical practice in a combination with traditional method.

3. OSCE should be applied in all nursing clinical examination.

4. Ensuring clear instructions and have revision related to all competencies and training for OSCE just before the examination.

\section{Reference}

[1]. Dharma R V, Pramod K R M, Rajaneesh R M , Hanumiah A, Shyam S P, Narasingha R T \& Kishore Babu SPV. Student evaluation of an OSCE in general medicine at Mamata medical college, Andhra Pradesh. International Journal of Medical Research\&Health Sciences, 2014; 3(2):342-345.

[2]. Harden RM: How to assess clinical competence - an overview. Med Teach, 1979;1:289-296.

[3]. Fowell SL\&, Bligh JG. Recent developments in assessing medical students. Postgrad Med J, 1998; 74:18-24. 
[4]. Ahmad C, Ahmad N\& Abu Baker R. Assessing Nursing Clinical Skills Performance Using Objective Structured Clinical Examination (OSCE) for Open Distance Learning Students in Open University Malaysia. International Conference on Information; Kuala Lumpur, 2009. 12-13 August.

[5]. Mahmoud G \&Mostafa M. The Egyptian Nursing Student's Perceptive view about an Objective Structured Clinical Examination (OSCE). Journal of American Science, 2011;7(4):730-738.

[6]. Alinier G. Nursing students'\& lecturers'perspectives of OSCE, incorporating simulation. 2009

[7]. Rushforth H E. Objective Structured Clinical Examination: Review Of Literature And Implication For Nursing Education. Nurse education today, 2007; 27:481-490. http://dx.doi.org/10.1016/j.nedt.2006.08.009

[8]. Walsh m, bailey hill P, \& koren I. Objective Structure Evaluation of Clinical Competence: An Integrative Review. Journal of advanced nursing, 2009; 65(8):1584-1595. http://dx.doi.org/10.1111/j.1365-2648.2009.05054.x

[9]. Kurz JM, Mohoney K, Plank LM \& Lidicker J. Objective Structured Clinical Examination And advanced Practice Nursing Students. Journal of Professional Nursing,2009; 25(3), 186- 191.

[10]. Selim A, Ramadan F, El-Gueneidy M \& Gaafer M. Using Objective Structured Clinical Examination (OSCE) in undergraduate psychiatric nursing education: Is it reliable and valid?. Nurse Education Today,(2012; (32): 283-288.

[11]. Health Workforce Development (HWD) Project Final report, Baseline survey- part I: Assessment of competency resulting from medical and nursing education in Egypt. Egypt Health Workforce Development Project (May 2006).

[12]. Eswi A , Samy A \& Shaliabe H . OSCE in Maternity and Community Health Nursing: Saudi Nursing Student's Perspective.American Journal of Research Communication,2013;1(3):143-162.

[13]. El-Nemer A \& Kandeel N.Using OSCE as an Assessment Tool for Clinical Skills: Nursing Students' Feedback.Australian Journal of Bas ic and Applied Sciences ,2009; 3(3): 2465-2472.

[14]. Munoz L, C.O'By rne, J. Pugsley \& Austin Z. Reliability, validity, and generalizability of an objective structured clinical examination (OSCE) for assessment of entry-to-practice in pharmacy. Pharmacy Education, 2005; 5(1): 33-43.

[15]. Rentschler D J, Eaton J, Cappiello S, McNally S,McNally \& McWilliam P. Evaluation of undergraduates students using objective structured clinical evaluation. Research Briefs,2007; 46(3): 135-139.

[16]. Robbin L \& Hoke M. Using Objective Structural Clinical Examinations to Meet Clinical Competence Evaluation Challenges with Distance Education Students. Perspectives in Psychiatric Care, 2008; 44(2):81-88.

[17]. AlsenanyS \& Al Saif A. Developing skills in managing Objective Structured Clinical Examinations (OSCE).Life Science Journal, 2012;9(3): 597-602.

[18]. Pierre R B , Wierenga A , Barton M , BrandayJ M and ChristieC DC .Student evaluation of an OSCE in paediatrics at the University of the West Indies, Jamaica. BMC Medical Education ,2004; 4:22.

[19]. Munkhondya TEM., Msiska G, Chilemba E and Majamanda MD . Experience of Conducting Objective Structured Clinical Evaluation (OSCE) in Malawi. Open Journal of Nursing, 2014; 4: 705-713. http://dx.doi.org/10.4236/ojn.2014.410075

[20]. Jones, Pegram A \& Fordham-Clarke C . Developing and Examining an Objective Structured Clinical Examination. Nurse Education Today, 2010; 30: 137-141. http://dx.doi.org/10.1016/j.nedt.2009.06.014

[21]. Alinier G. Nursing Students' and Lecturers' Perspectives of Objective Structured Clinical Examination Incorporating Simulation. Nurse Education Today, 2003; 23:419-426. http://dx.doi.org/10.1016/S0260-6917(03)00044-3

[22]. Rennie A \& Main M. Student Midwives' Views of the Objective Structured Clinical Examination. British Journal of Midwifery, 2006; 14: 602-607. http://dx.doi.org/10.12968/bjom.2006.14.10.21933

[23]. El-Gilany AH, Amr M \& Iqbal R. (2010). Students' attitudes toward psychiatry at Al-Hassa medical college, Saudi Arabia. Acad Psych.; 34:71-

[24]. Eldarir SA \& Abd el Hamid NA.Objective Structured Clinical Evaluation (OSCE) versus Traditional Clinical Students Achievement at Maternity Nursing: A Comparative Approach. IOSR Journal of Dental and Medical Sciences, 2013; 4, Issue 3 (Jan. - Feb. 2013): 63-68.

[25]. MaterEAM, Ahmed EI, ElSayedAA, El Shaikh MA \& Farag MK. The Impact of the Objective Structured Clinical Examination Approach for Clinical Evaluation Skills on the Student's Performance in Nursing College. World Journal of Medical Sciences,2014;11 (4): 609-613

[26]. Eftekhar H, Labaf A, Anvari P, Jamali A \&. Moghaddam S. Association of the preinternship Objective Structured Clinical Examination in final year medical students with comprehensive written examinations. Med education online, 2012;17: 1-7.

[27]. Abdel Nasser A, Mehdi A\& Abdel Kader A. Objective Structured Clinical Examination (OSCE) as an Assessment Tool for Clinical Skills in Sohag University: Nursing Students' perspective. Journal of Environment Studies, 2012;8: 59-69.

[28]. Delavar MA, Salmalian H, Faramarzi M, Pasha H, Bakhtiari A, Nikpour M and Ledari FM. Using the objective structured clinical examinations in undergraduate midwifery students.Journal of Medicine and Life ,2013;. 6 ( Issue 1):76-79.

[29]. Ryan S K, Stevenson \& Has s ell A. Assessment of clinical nurse specialists in rheumatology using an OSCE. Musculoskeletal Care, 2007; 5(3): 119-129.

[30]. Brosnan M, Evans W, Brosnan E and Brown G. Implementing Objective Structured Skills Evaluation (OSCE) in Nurse Registration Programmes in a Centre in Ireland: A Utilization Focused Evaluation. Nurse Education Today, 2006; 26: 115-122. http://dx.doi.org/10.1016/j.nedt.2005.08.003

[31]. Bakhsh TM, Sibiany AM, Al-Mashat FM, Meccawy AA \& Al-Thubaity FK. Comparison of students' performance in the traditional oral clinical examination and the objective structured clinical examination. Saudi Med J, 2009; 30: 555-557.

[32]. Milutinović D. Assessing clinical skill competence of nursing students through Objective Structured Clinical Examination. South Eastern Europe Health Sciences Journal (SEEHSJ), 2013; 3(1):13-18.

[33]. Mostafa A \& Amin T. Assessment Methods of an Undergraduate Psychiatry Course at a Saudi University. Sultan Qaboos Univ Med $\mathrm{J}, 2012 ; 12(2): 214-220$

[34]. Rentschler D J, Eaton J, Cappiello S, McNally S, McNally \& McWilliam P .Evaluation of undergraduate's students using objective structured clinical evaluation. Research Briefs, 2007; 46(3): 135-139.

[35]. Mitchell ML, Henderson A, Groves M, Dalton M \& Nulty D D . The Objective Structures Clinical Examination (OSCE): Optimizing Its Value in the Undergraduate Nursing Curriculum. Nurse Education Today, 2009; 29:398-404. http://dx.doi.org/10.1016/j.nedt.2008.10.007.

[36]. Raheel H \& Naeem N. Assessing the Objective Structured Clinical Examination: Saudi family medicine undergraduate medical students 'perceptions of the tool. JPMA, 2013;36: 1281-1283.

[37]. Jawaid M, Masood Z \& Jaleel F. Student's perception of surgical Objective Structured Clinical Examination (OSCE) at Dow University of health sciences. JPMI Journal, $2013 ; 28: 19-23$.

[38]. Valkenier B \& Marshall H. Student perception of a modified OSCE evaluation tool to assess their Clinical Lab Competence. Clinical Simulation in Nursing, 2014; 5: 129. 
[39]. Sharma M, Chandra P \& chaturvedi. Objective Structured Clinical Examination. Impact on Clinical and interpersonal Skills: Follow up study Indian Journal Psychological Medicine, 2013; 35: 299-301.

[40]. Smith V, Muldoon K, \& Biesty L. The Objective Structured Clinical Examination (OSCE) as a strategy for assessing clinical competence in midwifery education in Ireland: A critical review. Nurse Education in Practice, (2012); 12(5): 242-247. 